\title{
Penerapan Lima Model Kesetimbangan Adsorpsi Isoterm pada Adsorpsi Ion Logam Chrom VI oleh Zeolit
}

\section{Application of Five Isoterm Adsorption Equilibrium Models on Adsorption of Chrom VI Metal Ion by Zeolite}

\author{
Syarifah Aini ${ }^{\mathrm{a}^{*}}$, Supratikno $^{\mathrm{a}}$ \\ ${ }^{a}$ Jurusan Teknik Sipil, Universitas Widya Dharma Klaten \\ Jl. Ki Hajar Dewantara, Klaten 57438 , Jawa Tengah, Indonesia
}

\section{Artikel histori :}

Diterima 5 Oktober 2018 Diterima dalam revisi 15 Oktober 2018 Diterima 25 Oktober 2018 Online 31 Oktober 2018

\begin{abstract}
ABSTRAK: Ion logam chrom VI termasuk limbah logam berat yang perlu dilakukan pengolahan lebih lanjut dengan menggunakan adsorben. Zeolit adalah adsorben yang cocok untuk menyerap ion logam chrom VI karena zeolit merupakan mineral alam yang mempunyai luas permukaan aktif per satuan massa yang besar dan daya afinitas yang cukup kuat. Tujuan dari penelitian ini adalah menentukan model yang cocok untuk kesetimbangan adsorpsi ion logam chrom VI oleh zeolit beserta nilai parameternya, dan mengetahui daya serap zeolit optimal terhadap ion logam chrom VI. Penelitian ini mengunakan metode penerapan model kesetimbangan adsorpsi isoterm yang meliputi 5 persamaan yaitu Adsorpsi Linier (Henry's Law), Adsorpsi Isoterm Freundlich, Adsorpsi Isoterm Langmuir, Isoterm Brunauer-EmmettTeller (BET), Persamaan Sigmoidal Chapman. Dari kelima model ini dilakukan fitting data untuk mencari model yang lebih mendekati data. Pencocokan data dilakukan dengan minimasi yang dilakukan oleh program Matlab. Hasil penelitian menunjukkan bahwa model yang cocok yaitu model Adsorpsi Isoterm BET dengan nilai parameter yaitu nilai konstanta adsorpsi isoterm BET $\left(\mathrm{C}_{\mathrm{BET}}\right)$ sebesar 0,5183 1/mg, kapasitas maksimal adsorben saat setimbang secara teoritis (qs) adalah 149,9977 mg/g dan konsentrasi adsorbat jenuh pada lapisan monolayer (Cs) adalah $184,1691 \mathrm{mg} / \mathrm{l}$.
\end{abstract}

Kata Kunci: Adsorben; Isoterm BET; Model Kesetimbangan Adsorpsi; Zeolit

\begin{abstract}
Chrom VI metal ion include heavy metal waste which needs further processing using adsorbent. Zeolite is a suitable adsorbent for absorbing strong affinity chrom VI metal ions because zeolite is a natural mineral that has an active surface area per unit of mass and power. The purpose of this study was to determine a suitable model for the equilibrium adsorption of chrom VI metal ion by zeolite along with their parameter values, and to determine the optimal zeolite absorption against chrom VI metal ion. This study uses the method of applying the isotherm adsorption equilibrium model which includes 5 equations namely Linear Adsorption (Henry's Law), Freundlich Isotherm Adsorption, Langmuir Isoterm Adsorption, Brunauer-Emmett-Teller Isotherm (BET), Sigmoidal Chapman Equation. From these five models, data fitting is done to find models that are closer to the data. Data matching is done by minimizing the Matlab program. The results showed that the suitable model is the BET Isotherm Adsorption model with parameter values, namely the BET isotherm adsorption constant value $\left(\mathrm{C}_{\mathrm{BET}}\right)$ of $0.5183 \mathrm{l} / \mathrm{mg}$, the maximum capacity of the adsorbent at equilibrium theoretical (qs) is $149.9977 \mathrm{mg} / \mathrm{g}$ and the saturated adsorbate concentration in the monolayer (Cs) is $184.1691 \mathrm{mg} \mathrm{l}$.
\end{abstract}

Keywords: Adsorbent; BET Isotherm; Adsorption Equilibrium Model; Zeolite 


\section{Pendahuluan}

Limbah logam berat khususnya chromium merupakan limbah yang sering dibuang ke perairan oleh industri elektroplating, penyamakan kulit atau industri kimia yang lain karena limbah ini termasuk limbah yang proses pemisahan ion logamnya cukup sulit dipisahkan melalui proses pengendapan ataupun proses koagulasi. Oleh karenanya, maka limbah ini perlu dilakukan pengolahan lebih lanjut yaitu dengan proses adsorpsi. Adsorben yang digunakan dalam penelitian ini adalah zeolit, karena zeolit merupakan mineral alam yang mempunyai luas permukaan aktif per satuan massa yang besar dan mempunyai daya afinitas yang cukup kuat (Lestari, 2010).

Tujuan penelitian ini adalah menentukan model kesetimbangan adsorpsi ion logam chrom VI oleh zeolit beserta nilai-nilai parameternya, dan menggunakan model kesetimbangan adsorpsi yang cocok untuk menentukan daya serap zeolit optimal terhadap ion logam chrom VI melalui teori model kesetimbangan isoterm adsorpsi.

Meskipun adsorpsi dapat juga terjadi di permukaan adsorben padat, di dalam makropori dan mesopori, namun luas permukaaan ( surface area) adsorben padat sangat kecil sekali bila dibandingkan luas permukaan mikropori (internal surface area), sehingga ini biasanya diabaikan. Ketika laju adsorpsi sama dengan laju desorpsi maka kesetimbangan telah tercapai dan kapasitas adsorben dapat diketahui. Secara teori, kapasitas penjerapan suatu adsorben terhadap kontaminan dapat dihitung menggunakan persamaan isoterm adsorpsi (Metcalf dan Eddy, 2003).

Keberhasilan proses adsorpsi padat - cair tergantung pada performa adsorben yang digunakan, baik dalam hal kesetimbangan maupun kinetikanya. Adsorben dengan kapasitas yang tinggi (porous) tetapi memiliki afinitas yang rendah akan menjerap molekul cairan yang rendah, karena molekul cairan membutuhkan waktu yang lama untuk mencapai permukaan padatan. Sementara adsorben dengan afinitas yang tinggi tetapi pori - pori sedikit hanya mampu menjerap molekul cairan dalam jumlah sedikit, sehingga adsorpsi kurang sempurna (Laksito, 2008).

Jumlah adsorbat yang dapat terjerap oleh absorben merupakan fungsi dari karakteristik dan konsentrasi adsorbat serta temperatur. Karakteristik adsorbat seperti kelarutan, struktur molekul, berat molekul, polaritas dan hydrocarbon saturation merupakan hal yang penting. Pada umumnya, jumlah bahan yang teradsorpsi dapat dihitung sebagai fungsi dari konsentrasi pada temperatur konstan, dan fungsi ini dikenal sebagai Adsorption Isotherm (Metcalf dan Eddy, 2003).

Penelitian yang dilakukan oleh Murni Handayani dan Eko Sulistyono (2009) berjudul "Uji Langmuir dan Freundlich pada Penyerapan Limbah Chrom VI oleh Zeolit". Penelitian ini bertujuan mengetahui metoda adsorpsi isoterm yang sesuai untuk menentukan kapasitas maksimum adsorpsi zeolit terhadap limbah chrom VI. Persamaan yang digunakan dalam proses adsorpsi adalah persamaan adsorpsi Isoterm Langmuir dan Freundlich.
Alat yang digunakan dalam percobaan adalah Spektroskopi Serapan Atom (AAS). Hasil percobaan menunjukkan bahwa massa ion logam chrom VI terbesar yang teradsorpsi oleh zeolit adalah pada konsentrasi 20 ppm sebesar 7,71 mg / gram zeolit. Proses penyerapan limbah chrom VI oleh zeolit mengikuti persamaan Langmuir dan Freundlich dengan $\mathrm{R}^{2}>0,9$. Persamaan yang cocok untuk menentukan kapasitas adsorpsi maksimum zeolit pada proses penyerapan limbah chrom VI adalah persamaan Langmuir. Kapasitas adsorpsi maksimum adalah $52,25 \mathrm{mg} / \mathrm{gram}$.

\section{Metode Penelitian}

\subsection{Metode Pengambilan Data Sekunder}

Data Sekunder diambil dari data penelitian yang dilakukan oleh Handayani dan Sulistyono (2009), data yang didapat adalah konsentrasi ion logam chrom VI pada saat setimbang $\left(C_{e}\right)$ dan konsentrasi ion logam chrom VI yang teradsorpsi oleh zeolit pada saat setimbang $\left(q_{e}\right)$ pada berbagai konsentrasi ion logam chrom VI dalam sampel mula-mula $\left(C_{0}\right)$ yaitu konsentrasi 5 ppm, 10 ppm, 15 ppm, dan $20 \mathrm{ppm}$.

Dari data sekunder ini dilakukan fitting data dengan menggunakan program Matlab yang sudah dibuat berdasarkan model kesetimbangan adsorpsi isoterm, kemudian model yang cocok akan dapat diamati dari visualisasi dan minimasi SSE (sum square error). Model yang cocok dapat digunakan untuk mengestimasi daya serap zeolit optimal terhadap ion logam chrom VI.

\subsection{Model dan Analisis Data}

Model yang dipakai dalam penelitian ini adalah model kesetimbangan adsorpsi isotherm yang meliputi 5 persamaan yaitu Adsorpsi Linier (Henry's Law), Adsorpsi Isoterm Freundlich, Adsorpsi Isoterm Langmuir, Isoterm Brunauer-Emmett-Teller (BET), Persamaan Sigmoidal Chapman. Dari kelima model ini dilakukan fitting data untuk mencari model yang lebih mendekati data.

Data yang didapat adalah konsentrasi ion logam chrom VI pada saat setimbang $\left(C_{e}\right)$ dan konsentrasi ion logam chrom VI yang teradsorpsi oleh zeolit pada saat setimbang $\left(q_{e}\right)$ pada berbagai konsentrasi ion logam chrom VI dalam sampel mula-mula $\left(C_{0}\right)$ yaitu konsentrasi 5 ppm, 10 ppm, 15 ppm, dan 20 ppm.

Adsorpsi linier (Henry's Law) berlaku pada sistem larutan yang sangat encer dan dinyatakan sebagai (Noll,dkk., 1992) :

$$
q_{e}=K_{.} C_{e}
$$

di mana $q_{e}$ adalah konsentrasi zat yang terserap pada adsorben saat setimbang $(\mathrm{mg} / \mathrm{g}), \mathrm{K}$ adalah konstanta isoterm $(\mathrm{l} / \mathrm{g})$ dan $C_{e}$ adalah konsentrasi zat pada larutan saat setimbang $(\mathrm{mg} / \mathrm{l})$.

Persamaan Freundlich berasumsi bahwa adsorpsi terjadi secara multilayer dan permukaan adsorben heterogen. Persamaan isoterm Freundlich dinyatakan sebagai (Metcalf dan Eddy, 2003) :

$$
q_{e}=\frac{x}{m}=K_{f} C_{e} \frac{\dot{i}}{n}
$$


dimana $q_{e}$ adalah massa bahan yang teradsorpsi $(x)$ per massa adsorben $(m)$ pada saat setimbang $(\mathrm{mg} / \mathrm{g}), K_{f}$ adalah tetapan kesetimbangan Freundlich $(1 / \mathrm{g}), \quad C_{e}$ adalah konsentrasi adsorbate dalam fase cair pada saat setimbang (mg/l) dan 1/n adalah parameter intensitas Freundlich.

Persamaan Langmuir berdasarkan asumsi bahwa adsorpsi terjadi secara monolayer, bersifat reversible dan dinyatakan sebagai (Metcalf dan Eddy, 2003) :

$$
q_{e}=\frac{x}{m}=\frac{a b C_{e}}{1+b C_{e}}
$$

di mana $a$ adalah konsentrasi maksimal di fase padat $(\mathrm{mg} / \mathrm{g})$ dan $b$ adalah tetapan kesetimbangan $(1 / \mathrm{mg})$.

Isoterm BET mempunyai asumsi yang sama seperti teori Langmuir, yaitu permukaan homogen dan tidak ada interaksi antar molekul teradsorpsi dan dirumuskan sebagai berikut (Foo dan Hameed, 2010):

$$
q_{e}=\frac{q_{s} C_{B E T} C_{e}}{\left(C_{s}-C_{e}\right)\left[1+\left(C_{B E T}-1\right)\left(C_{e} / C_{s}\right)\right]}
$$

di mana $C_{B E T}$ adalah konstanta adsorpsi isoterm BET (l/mg), $C_{s}$ adalah konsentrasi adsorbat jenuh pada lapisan monolayer $(\mathrm{mg} / \mathrm{l}), q_{e}$ adalah konsentrasi adsorbat yang terjerap dalam adsorben saat setimbang $(\mathrm{mg} / \mathrm{g})$ dan $q_{s}$ adalah kapasitas maksimal adsorben saat setimbang secara teoritis $(\mathrm{mg} / \mathrm{g})$.

Persamaan Chapman menyatakan adsorpsi sangat kecil pada konsentrasi rendah namun adsorpsi akan meningkat dengan semakin meningkatnya konsentrasi larutan, persamaan sigmoidal Chapman dinyatakan sebagai
(Chatterjee,dkk., 2010):

$$
q_{e}=\propto\left(1-e^{-\beta \cdot c_{x}}\right)^{Y}
$$

dimana $\alpha$ adalah konsentrasi maksimal adsorben $(\mathrm{mg} / \mathrm{g})$ dan $\beta, \gamma$ adalah tetapan kesetimbangan.

Kadar chromium yang teradsorpsi oleh zeolit pada saat setimbang dihitung dengan menggunakan persamaan berikut :

$$
q_{e}=\left(\frac{V}{m}\right) \cdot C_{0}+q_{e 0}-\left(\frac{V}{m}\right) \cdot C_{e}
$$

dimana $q_{e}$ adalah massa chrom yang teradsorpsi $(x)$ per massa zeolit $(m)$ pada saat setimbang ( $\mathrm{mg} \mathrm{C} / \mathrm{g}$ zeolit), $\mathrm{q}_{\mathrm{eo}}$ adalah konsentrasi chrom di dalam zeolit mula - mula (mg C/ g zeolit), $C_{o}$ adalah konsentrasi chrom dalam cairan mula-mula $(\mathrm{mg} / \mathrm{l}), m$ adalah massa zeolit $(g), V$ adalah volume cairan (l), $C_{e}$ adalah konsentrasi chrom dalam cairan saat setimbang $(\mathrm{mg} / \mathrm{l})$.

\section{Hasil dan Pembahasan}

Kesetimbangan adsorpsi merupakan informasi penting yang dapat menunjukkan distribusi molekul adsorbat pada fase cair dan padat ketika proses adsorpsi mencapai kesetimbangan. Percobaan kesetimbangan adsorpsi pada berbagai jenis ukuran partikel zeolit dilakukan untuk mengetahui kondisi optimum zeolit dalam menyerap ion logam Chrom VI. Hasil olah data percobaan pada berbagai model kesetimbangan disajikan pada Tabel 1.

Tabel 1. Hasil Olah Data Adsorpsi Ion Chrom VI oleh Zeolit pada Berbagai Model Kesetimbangan

\begin{tabular}{cccccccc}
\hline $\begin{array}{c}\text { Co } \\
\text { data } \\
(\mathrm{ppm})\end{array}$ & $\begin{array}{c}\text { Ce data } \\
(\mathrm{ppm})\end{array}$ & $\begin{array}{c}\text { qe } \\
\text { data } \\
(\mathrm{mg} / \mathrm{g})\end{array}$ & $\begin{array}{c}\text { Henry } \\
\text { qe hitung } \\
(\mathrm{mg} / \mathrm{g})\end{array}$ & $\begin{array}{c}\text { Freundlich } \\
\text { qe hitung } \\
(\mathrm{mg} / \mathrm{g})\end{array}$ & $\begin{array}{c}\text { Langmuir } \\
\text { qe hitung } \\
(\mathrm{mg} / \mathrm{g})\end{array}$ & $\begin{array}{c}\text { BET } \\
\text { qe hitung } \\
(\mathrm{mg} / \mathrm{g})\end{array}$ & $\begin{array}{c}\text { Chapman } \\
\text { qe hitung } \\
(\mathrm{mg} / \mathrm{g})\end{array}$ \\
\hline 5 & 4,11 & 1,78 & 1,92 & 2,62 & 2,04 & 1,79 & 1,15 \\
10 & 8,15 & 3,70 & 3,81 & 4,18 & 3.92 & 3,68 & 4,14 \\
15 & 12,13 & 5,74 & 5,67 & 5,48 & 5,66 & 5,66 & 6,28 \\
20 & 16,14 & 7,71 & 7,54 & 6,65 & 7,32 & 7,80 & 7,37 \\
\hline
\end{tabular}

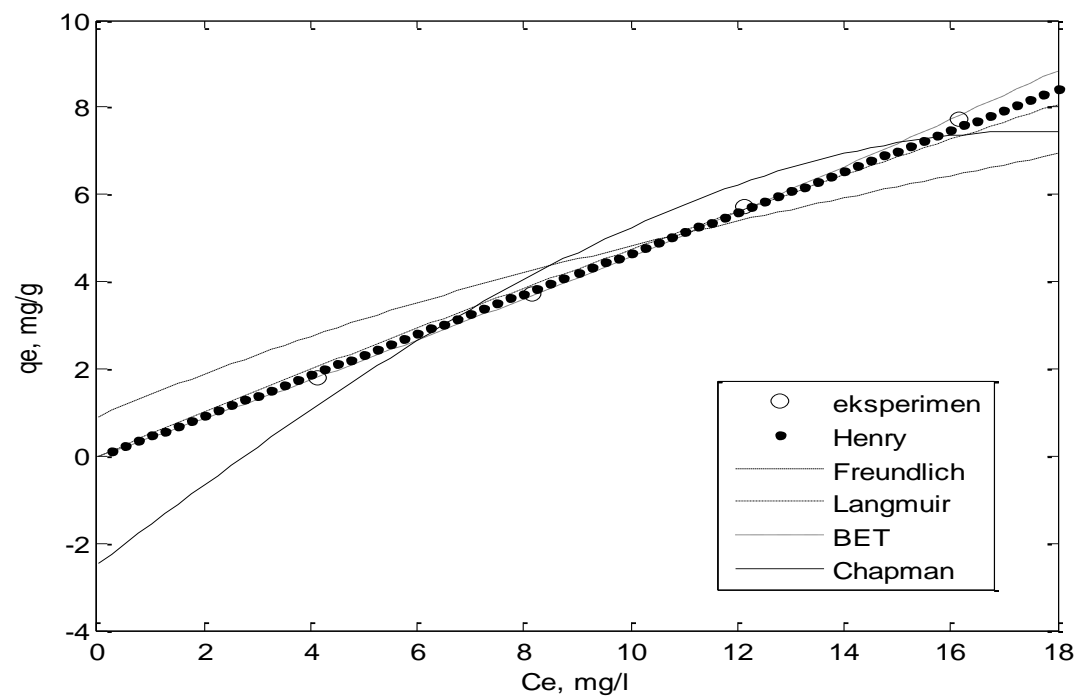

Gambar 1. Kesetimbangan Ion Chrom VI dalam Zeolit pada Berbagai Model 
Tabel 2. Nilai Parameter Masing-Masing Model Kesetimbangan

\begin{tabular}{|c|c|c|}
\hline $\begin{array}{c}\text { Model } \\
\text { Kesetimbangan }\end{array}$ & \multicolumn{2}{|c|}{ Konstanta } \\
\hline \multirow[t]{2}{*}{ Henry } & $\mathrm{K}(1 / \mathrm{g})$ & 0,4671 \\
\hline & SSE & 0,0655 \\
\hline \multirow[t]{3}{*}{ Freundlich } & $\mathrm{Kf}(1 / \mathrm{g})$ & 0,9957 \\
\hline & $\mathrm{n}$ & 1,4635 \\
\hline & SSE & 2,1272 \\
\hline \multirow[t]{3}{*}{ Langmuir } & $\mathrm{a}(\mathrm{mg} / \mathrm{g})$ & 63,4667 \\
\hline & b (l/mg) & 0,0081 \\
\hline & SSE & 0,2745 \\
\hline \multirow[t]{4}{*}{ BET } & qs ( mg/g) & 149,9993 \\
\hline & $\mathrm{C}_{\mathrm{BET}}(\mathrm{l} / \mathrm{mg})$ & 0,5183 \\
\hline & $\mathrm{Cs}(\mathrm{mg} / \mathrm{l})$ & 184,1691 \\
\hline & SSE & 0,015 \\
\hline \multirow[t]{4}{*}{ Chapman } & $\alpha(\mathrm{mg} / \mathrm{g})$ & 8,2002 \\
\hline & $\beta$ & 0,2227 \\
\hline & $\gamma$ & 3,844 \\
\hline & SSE & 0,9977 \\
\hline
\end{tabular}

Dari Tabel 1 dan Gambar 1 dapat diamati bahwa semakin tinggi konsentrasi ion logam chrom VI, maka akan semakin banyak ion logam chrom VI yang teradsorpsi. Hal ini disebabkan dengan semakin tinggi konsentrasi ion logam chrom VI akan semakin banyak ion yang berinteraksi dengan rongga-rongga zeolit sehingga ion-ion tersebut akan lebih banyak terserap oleh zeolit pada keseimbangan tertentu dan menyebabkan tingkat adsorpsinya semakin besar.

Secara visual pada Gambar 1 dapat dilihat bahwa garis model yang lebih mendekati data percobaan adalah model Henry, Langmuir dan BET. Sedangkan pada Tabel 2 nilai SSE yang paling kecil adalah nilai SSE pada model BET. Kedua hal ini bisa dijadikan pertimbangan untuk menentukan model mana yang paling cocok untuk proses kesetimbangan adsorpsi ion logam chrom VI oleh zeolit. Maka dalam hal ini akan kita bahas satu per satu model mana yang tepat dan dapat digunakan untuk mewakili proses kesetimbangan ini, dengan menampilkan berbagai grafik pada berbagai model kesetimbangan yang telah diajukan dalam penelitian ini.

\section{Model Henry}

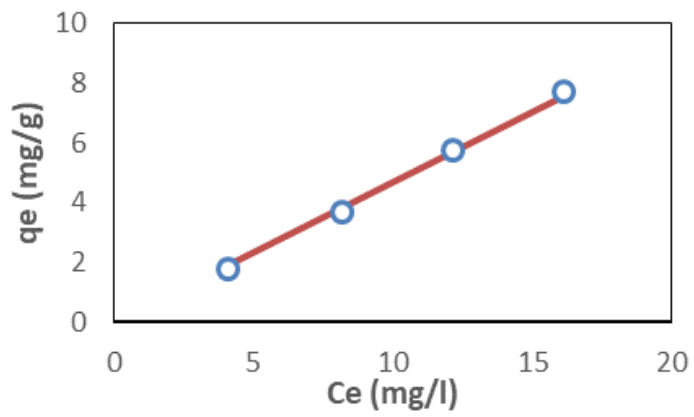

Gambar 2. Kesetimbangan Ion Chrom VI dalam Zeolit pada Model Henry
Adsorpsi linier model Henry berlaku untuk sistem larutan yang sangat encer (Noll,dkk., 1992). Untuk kasus penelitian ini adalah larutan encer bila konsentrasi ion logam chrom VI dalam larutan kecil, tapi apabila konsentrasi ion logam chrom VI meningkat, maka larutannya menjadi pekat. Maka dalam hal ini model Henry tidak dapat dijadikan model yang dapat mewakili kasus penelitian ini

\section{Model Freundlich}

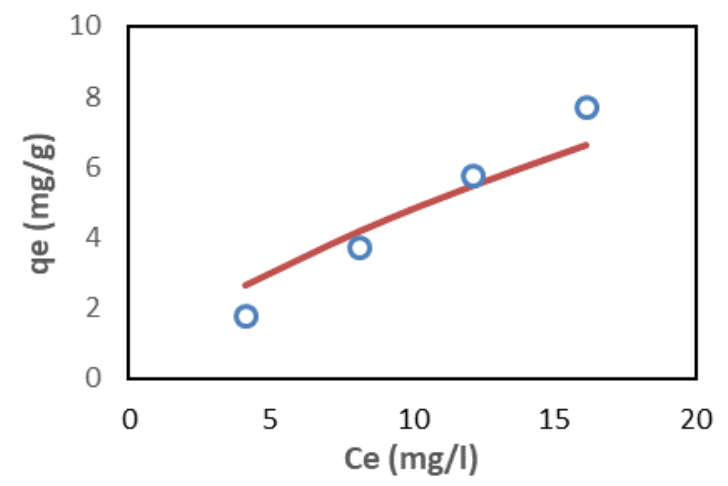

Gambar 3. Kesetimbangan Ion Chrom VI dalam Zeolit pada Model Freundlich

Gambar 3 memperlihatkan bahwa model Freundlich tidak mendekati data percobaan atau eksperimen dari proses kesetimbangan adsorpsi ion logam chrom VI oleh zeolit, hal ini terlihat nilai $S S E=2,1272$, nilai tetapan kesetimbangan Freundlich $\left(K_{f}\right)$ sebesar 0,9957 1/g dan nilai parameter intensitas Freundlich $(1 / \mathrm{n})=0,6833$.

Persamaan Freundlich berasumsi bahwa adsorpsi terjadi secara multilayer pada permukaan adsorben, valid digunakan untuk adsorpsi fisik dan cocok untuk adsorpsi konsentrasi sedang (Do, 1998 dan Noll,dkk., 1992). Hal ini tidak cocok dengan kasus penelitian ini bahwa adsorpsi terjadi secara kimia dan monolayer. Maka dapat dilihat dengan visual gambar bahwa antara data percobaan dengan model Freundlich tidak ada kedekatan, sehingga disimpulkan bahwa model Freundlich tidak cocok untuk kasus penelitian ini.

\section{Model Langmuir}

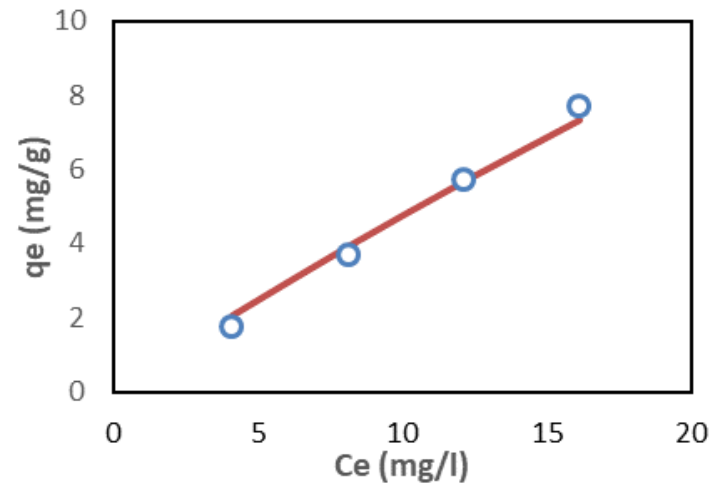

Gambar 4. Kesetimbangan Ion Chrom VI dalam Zeolit pada Model Langmuir 
Dari Gambar 4 terlihat bahwa model Langmuir mendekati data percobaan atau eksperimen dari proses kesetimbangan adsorpsi ion logam chrom VI oleh zeolit, dengan nilai SSE $=0,2745$ dan nilai konstanta kesetimbangan Langmuir (b) sebesar 0,0081 1/mg dan konsentrasi maksimal zeolit (a) adalah $63,4467 \mathrm{mg} / \mathrm{g}$.

Adsorpsi isoterm Langmuir menggambarkan kondisi kesetimbangan antara permukaaan dan larutan yang dapat bersifat bolak-balik (reversible) dan berlaku untuk adsorpsi lapis tunggal (monolayer) pada permukaan yang homogen (Do, 1998). Teori Langmuir ini cocok dengan kondisi kasus penelitian ini, maka teori ini bisa dijadikan rujukan atau model dalam penelitian ini. Hal ini serupa dengan penelitian sebelumnya yang dilakukan oleh Murni Handayani dan Eko Sulistyono (2009), menyimpulkan bahwa persamaan yang cocok untuk menentukan kapasitas adsorpsi maksimum zeolit pada proses penyerapan limbah chrom VI adalah persamaan Langmuir. Kapasitas adsorpsi maksimum diperoleh $52,25 \mathrm{mg}$ /gram.

Tapi dilihat dari hasil visual gambar dan SSE masih ada teori lain yang dapat dikaji dan lebih cocok untuk kasus penelitian ini.

\section{Model BET}

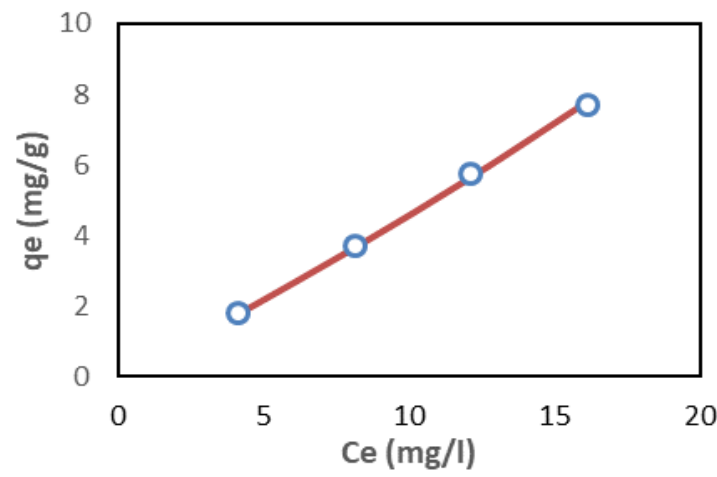

Gambar 5. Kesetimbangan Ion Chrom VI dalam Zeolit pada Model BET

Dari Gambar 5 terlihat bahwa model BET sangat mendekati data percobaan atau eksperimen dari proses kesetimbangan adsorpsi ion logam chrom VI oleh zeolit, dengan nilai $S S E=0,015$, nilai konstanta adsorpsi isoterm BET $\left(C_{B E T}\right)$ sebesar $0,5183 \mathrm{l} / \mathrm{mg}$, kapasitas maksimal adsorben saat setimbang secara teoritis $\left(q_{s}\right)$ adalah $149,9977 \mathrm{mg} / \mathrm{g}$ dan konsentrasi adsorbat jenuh pada lapisan monolayer $\left(C_{s}\right)$ adalah $184,1691 \mathrm{mg} / \mathrm{l}$.

Teori BET mempunyai asumsi yang sama seperti teori Langmuir, yaitu permukaan adsorben homogen dan tidak ada interaksi antar molekul teradsorpsi (Foo dan Hameed, 2010). Model BET ini lebih cocok menggambarkan dalam kasus penelitian ini, hal ini dapat dilihat dari gambar yaitu kedekatan model dan data percobaan, disertai dengan nilai SSE yang paling kecil.

Selain itu, model BET ini mampu menggambarkan seberapa besar konsentrasi adsorbat jenuh pada lapisan monolayer, yang tidak dapat digambarkan oleh model lain, termasuk isoterm Langmuir.

\section{Model Chapman}

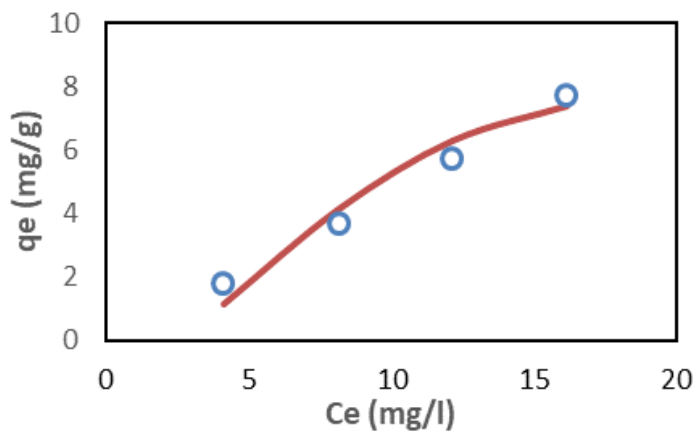

Gambar 6. Kesetimbangan Ion Chrom VI dalam Zeolit pada Model Chapman

Dari Gambar 6 terlihat bahwa model Chapman kurang mendekati data percobaan atau eksperimen dari proses kesetimbangan adsorpsi ion logam chrom VI oleh zeolit, dengan nilai $\mathrm{SSE}=0,9977$, nilai tetapan kesetimbangan $(\beta)$ sebesar 0,2227 , nilai tetapan kesetimbangan $(\gamma)$ adalah 3,8449 dan konsentrasi maksimal adsorben $(\alpha)$ adalah $8,2002 \mathrm{mg} / \mathrm{g}$.

Model Chapman menyatakan adsorpsi sangat kecil pada konsentrasi rendah namun adsorpsi akan meningkat dengan semakin meningkatnya konsentrasi larutan. Hal ini disebabkan adanya reaksi lain dalam larutan seperti reaksi kompleksasi dengan ligan, mengakibatkan penjerapan adsorbat menjadi terhambat, dan adanya gaya tarik menarik antar adsorbat yang mengakibatkan terjadi adsorpsi gabungan (cooperative adsorption) (Chatterjee,dkk., 2010). Fenomena ini tidak terjadi dalam kasus penelitian ini, maka model Chapman tidak dapat dijadikan rujukan untuk kasus penelitian ini.

\section{Kesimpulan}

Secara visual gambar dari kelima grafik kesetimbangan ion logam chrom VI dalam zeolit, model yang mendekati data eksperimen ada 3 model yaitu model Henry, model Langmuir, dan model BET. Model BET ditentukan sebagai model yang cocok untuk mewakili proses kesetimbangan adsorpsi ion logam chrom VI oleh zeolit, karena model ini mampu menggambarkan seberapa besar konsentrasi adsorbat jenuh pada lapisan monolayer pada permukaan yang homogen. Nilai parameter dari model BET adalah nilai konstanta adsorpsi isoterm BET $\left(\mathrm{C}_{\mathrm{BET}}\right)$ sebesar 0,5183 1/mg, kapasitas maksimal adsorben saat setimbang secara teoritis (qs) adalah 149,9977 mg/g dan konsentrasi adsorbat jenuh pada lapisan monolayer (Cs) adalah 184,1691 mg/l. Maka estimasi nilai daya serap zeolit optimal dapat ditentukan dari model BET sebesar 149,9977 mg/g.

\section{Ucapan Terima kasih}

Terima kasih penulis sampaikan kepada Universitas Widya Dharma Klaten, sebagai tempat kami melakukan penelitian ini, dan kepada Kemenristek Dikti sebagai penyandang dana dalam penelitian ini, dan juga semua pihak yang telah banyak membantu dalam penyelesaian penelitian ini. 


\section{Daftar Pustaka}

Chatterjee, S., Dae, S., Lee, Min, W., Seung, H., dan Woo. (2010). Enhanced Molar Sorption Ratio for Naphthalene through the Impregnation of Surfactant into Chitosan Hydrogel Beads. Bioresour. Technol. 101, 4315-4325.

Do, D.D. (1998). Adsorption Analysis: Equilibria and Kinetics. London: Imperial College Press.

Foo, K.Y., dan Hameed, B.H. (2010). Review Insights Into the Modeling of Adsorption Isotherm Systems. Chem. Eng. J. 156, 2-10.

Handayani, M., dan Sulistyono, E. (2009). Uji Persamaan Langmuir dan Freundlich pada Penyerapan Limbah Chrom VI oleh Zeolit. Prosiding Seminar Nasional Sains dan Teknologi Nuklir
PTNBR - BATAN Bandung. 3 Juni 2009, 130136.

Hinz, C. (2001). Description of Sorption Data with Isotherm Equations. Geoderma 99, 225-243.

Laksito, D.(2008). Kesetimbangan Fasa Amonia pada Air dan Sedimen di Sungai (Tesis). Tersedia dari Digital Library UGM Yogyakarta.

Lestari, D.Y. (2010). Kajian Modifikasi dan Karakteristik Zeolit Alam dari Berbagai Negara. Prosiding Seminar Nasional Kimia dan Pendidikan Kimia 2010 Yogyakarta. 30 Oktober 2010.

Metcalf dan Eddy. (2003). Wastewater Engineering Treatment and Reuse. (Fourth edition). New York: Mc. Graw hill.

Noll, K.E., Gounaris, V., dan Wang, S.H. (1992). Adsorption Technology for Air and Water Pollution Control, USA: Lewis Publisher, Inc 